\title{
Primary care clinicians' attitudes towards point-of-care blood testing: a systematic review of qualitative studies
}

\author{
Caroline HD Jones ${ }^{1 *}$, Jeremy Howick', Nia W Roberts², Christopher P Price ${ }^{1}$, Carl Heneghan?', \\ Annette Plüddemann ${ }^{1}$ and Matthew Thompson ${ }^{1}$
}

\begin{abstract}
Background: Point-of-care blood tests are becoming increasingly available and could replace current venipuncture and laboratory testing for many commonly used tests. However, at present very few have been implemented in most primary care settings. Understanding the attitudes of primary care clinicians towards these tests may help to identify the barriers and facilitators to their wider adoption. We aimed to systematically review qualitative studies of primary care clinicians' attitudes to point-of-care blood tests.

Methods: We systematically searched Medline, Embase, ISI Web of Knowledge, PsycINFO and CINAHL for qualitative studies of primary care clinicians' attitudes towards point-of-care blood tests in high income countries. We conducted a thematic synthesis of included studies.

Results: Our search identified seven studies, including around two hundred participants from Europe and Australia. The synthesis generated three main themes: the impact of point-of-care testing on decision-making, diagnosis and treatment; impact on clinical practice more broadly; and impact on patient-clinician relationships and perceived patient experience. Primary care clinicians believed point-of-care testing improved diagnostic certainty, targeting of treatment, self-management of chronic conditions, and clinician-patient communication and relationships. There were concerns about test accuracy, over-reliance on tests, undermining of clinical skills, cost, and limited usefulness.

Conclusions: We identified several perceived benefits and barriers regarding point-of-care tests in primary care. These imply that if point-of-care tests are to become more widely adopted, primary care clinicians require evidence of their accuracy, rigorous testing of the impact of introduction on patient pathways and clinical practice, and consideration of test funding.
\end{abstract}

Keywords: Primary health care, Point of care technology, Diagnosis, Qualitative research, Systematic review

\section{Background}

Point-of-care tests (POCTs, also known as near-patient tests) have been used for many years, for example blood glucose and urine testing; yet recently there has been an explosion in the development of these technologies [1,2]. POCTs are usually delivered during a clinical visit; the results are available quickly without the need to send samples to a laboratory. In primary care this could offer alternatives to traditional laboratory testing, with the

\footnotetext{
*Correspondence: caroline.jones@phc.ox.ac.uk

'Department of Primary Care Health Sciences, University of Oxford, Woodstock Road, Oxford, UK

Full list of author information is available at the end of the article
}

potential to maintain or improve patient convenience, satisfaction and health outcomes whilst saving time and costs [3-7]. However there are also potential disadvantages including time needed to use them, inaccurate tests, and inappropriate testing $[5,8]$.

Despite their availability and potential to improve patient care, POCTs have not been widely adopted in primary care in most countries. Exploring why this is the case requires (among other things) a clearer understanding of the attitudes of primary care clinicians to the use of these tests, including any concerns they may have. We aimed to gain an understanding of primary care clinicians' attitudes towards POCTs by conducting a systematic

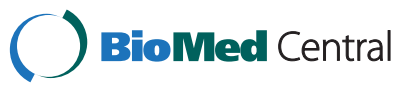


review. This paper reports the results of that systematic review and synthesis of qualitative studies.

\section{Methods}

\section{Literature search and study selection}

We conducted a systematic search for primary qualitative research articles exploring attitudes of any type of primary care clinicians towards POCTs. We defined POCTs as any test where the results are available during a clinical visit, without the need to send sample to a laboratory. We included only studies on POCTs involving blood (excluding other types of sample such as urine or throat swabs) because these could replace venipuncture and laboratory testing, and have the biggest potential to change practice; and attitudes towards them may differ to attitudes towards other types of POCT. We limited our search to primary care and high income country settings (defined by the Organisation for Economic Cooperation and Development) - excluding studies in emergency department, hospital or low or middle income country settings - since attitudes may be specific to different contexts. We included only studies which used qualitative data and analyses, because qualitative data enables indepth understanding of the range of attitudes of participants from their perspectives. Studies where qualitative data and analyses were embedded within larger mixed methods studies were included only if we could extract the qualitative data. Where studies reported attitudes of secondary care clinicians or patients in addition to primary care clinicians, we extracted and synthesized data relating to primary care clinicians only.

We searched Medline (1948-present), Embase (1974present), ISI Web of Knowledge (1945-present), PsycINFO (1967-present) and CINAHL (1980-present) from database start date to February 2013. The search was developed through an iterative process combining search terms that best describe our search criteria, including free-text terms and subject headings to reflect the following concepts: 'point of care test' and 'primary care'. Validated search filters were adapted to focus the search to qualitative research papers (for example Wong et al. for Medline [9]). In addition we scanned reference lists of included studies. The search strategy included a search for previously conducted reviews in order to identify primary studies from any relevant previous reviews [10] (see Additional file $1 \mathrm{~A}$ for Medline search strategy).

Two authors $(\mathrm{CJ}, \mathrm{JH})$ independently assessed the studies for eligibility. Titles were independently screened by both authors and those that were obviously not relevant were excluded. Both authors independently examined the full text of all remaining studies, and those that did not meet the inclusion criteria were excluded. Discrepancies regarding inclusion were resolved by discussion with a third reviewer (MT) until agreement was reached.

\section{Data synthesis}

Systematic review of qualitative evidence has become popular in recent years [11]. There are a number of methods for synthesizing findings from qualitative studies [12]: we conducted thematic synthesis, which is able to integrate the findings of multiple qualitative studies and generate new concepts and hypotheses $[13,14]$.

Two authors $(\mathrm{CJ}, \mathrm{JH})$ independently extracted data on study characteristics and context from included studies using a standardized data extraction sheet. We also independently extracted the study results/findings, including the primary data reported in studies (participant responses) as well as authors' summaries and interpretations. After familiarizing ourselves with the findings of individual studies we developed codes, and assigned sections of findings to these codes. Codes were then grouped into descriptive themes. Codes and themes were not determined a priori but were driven by the data. From the descriptive themes we generated analytical themes reflecting new insights going beyond the findings of the included studies [14]. Themes were discussed amongst all authors and consensus reached. We reflected critically on how our own backgrounds and assumptions impacted our interpretation of the data, and compared the results of our synthesis with the conclusions of individual studies to verify our findings.

The same authors $(\mathrm{CJ}, \mathrm{JH})$ appraised study quality using a checklist based on the criteria described by Kuper and colleagues [15]. The checklist included items on whether the sample, data and analysis were appropriate; the results can be transferred across settings; ethical issues were adequately addressed; and it is clear what the researchers did. We took account of study quality when interpreting the findings, by being more cautious when interpreting the results of low quality studies and highlighting possible limitations.

\section{Results}

\section{Search results}

The search revealed 472 potentially eligible studies. After title screening, 429 were excluded, and a further 36 were excluded after assessing the full text (see Figure 1).

\section{Characteristics of included studies}

We included seven studies [16-22] with a total of around 200 participants (see Table 1). They took place in Europe $(n=6)$ and Australia $(n=1)$. One was published in 1997, and the remainder were published between 2007 and 2011. All used semi-structured interviews to gather data; two also used focus groups. The 1997 study referred to blood POCTs using samples obtained by venipuncture and analysed onsite in the health centre [19]; the others referred to finger-prick blood tests. All examined attitudes of general practitioners (GPs); two also examined attitudes of nurses. 


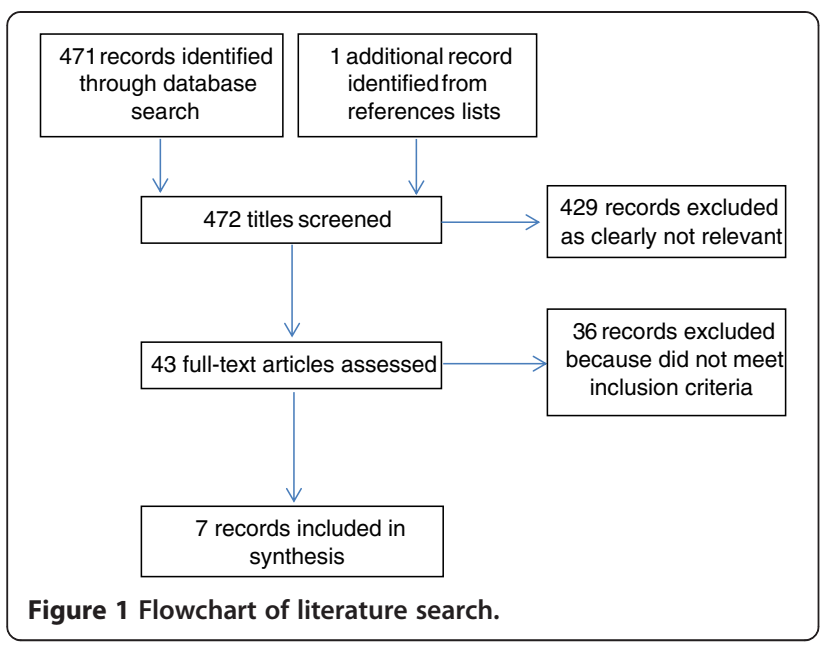

Two studies used data obtained from interviews with GPs participating in the same randomised trial $[17,18]$. Each had 20 participants, 10 of whom overlapped between the two studies. Since both had 10 different participants, and the focus of analyses were different, we included both in our synthesis.

The type of test included in each study is shown in Table 1. Four studies examined attitudes towards Creactive protein (CRP) POCTs or hypothetical tests which could similarly distinguish between viral and bacterial infections [16-18,22]: we refer to these as diagnostic. Two examined POCTs for monitoring chronic illness (patients with diabetes [21] and those taking warfarin [20]): we refer to these as monitoring. One examined attitudes towards a range of POCTs [19]. We looked for similarities and differences in attitudes towards diagnostic and monitoring POCTs.

Studies varied according to whether participants had experience using POCTs, were being asked about a test of which they had no experience, or contained a combination of those with and without experience (Table 1). Three studies including participants with experience were conducted in the context of a randomised trial in which a test was introduced as an intervention to all $[17,21]$ or some [18] participants, and one included GPs from a health centre where POCTs were being piloted [19]. Another included GPs from Norway, where CRP POCTs are routinely used, and from eight other European countries where they are not [22]. We looked at similarities and differences in attitudes between clinicians with different levels of experience.

Five of the included studies were of good quality (see Table 2) [16-18,21,22]. Study samples, data collection and analyses were appropriate and they were clearly described. Another study lacked some details about the sample (for example how many of the participants were GPs and nurses, and whether they had any experience at all of using POCTs), and the sample size was small (only one focus group for each group of clinicians); but the methods of data collection and analysis were appropriate [20]. We considered these studies to be relatively equally rigorous and trustworthy and treated them equally in the synthesis. One other study was poorly described [19]: it lacked details including the number of participants; the design, duration and timing of the interviews and focus group; how the data were analysed and by whom; and whether the results include verbatim quotes or not. Therefore it is not possible to assess how rigorous and trustworthy the study is. Therefore, this study did not contribute as much to the synthesis. Additionally of note when interpreting the results of this study, the nature of the POCT in this study differed from the others in our synthesis because it used blood obtained by venipuncture rather than finger-prick blood samples.

Amongst all studies there was a lack of discussion about the impact of researchers' characteristics and perspectives, and their relationships with participants. This absence of reflexivity limits our ability to assess the influence of the researchers on the data and interpretations.

Through the synthesis we identified descriptive themes regarding positive and negative attitudes of primary care clinicians towards blood POCTs. From these, we developed three analytical themes which are discussed below. Within each of these themes there are issues which may act as facilitators and barriers to widespread adoption of POCTs in primary care: Table 3 summarises the barriers and facilitators to POCT use within each theme.

1) Impact of POCTs on decision-making, diagnosis and treatment

Many attitudes were related to how POCTs might enhance immediate diagnosis and treatment. Diagnostic POCTs were viewed as helpful for improving diagnostic certainty and confidence in clinical decisions; [16-18,22] particularly for ruling out serious infections [17].

POCTs were perceived to enable more effective targeting of treatment. Particularly, tests which could distinguish viral from bacterial infections were considered helpful and could aid decision-making regarding antibiotic prescription: [16-18,22]. "It also helps you to be a bit more careful in prescribing antibiotics, that's true. It makes you more aware that you may be using them too often" (GP [17]). This was a belief of GPs who had both used $[17,22]$ and not used diagnostic POCTs $[16,18,22]$.

A primary concern was the analytical accuracy of POCTs $[16,19,20,22]$ : "the results they give are not accurate enough" (Primary Care Clinician [22]), which might lead clinicians to miss serious infections [22]. Clinicians did not feel 'convinced' or confident about their performance [16,20]: "we've had no research presented to us" (Nurse 
Table 1 Characteristics of included studies

\begin{tabular}{|c|c|c|c|c|c|c|}
\hline $\begin{array}{l}\text { Primary author } \\
\text { (year) }\end{array}$ & Country & Type of study & Type of POCT & Participants' experience of using POCTs & $\begin{array}{l}\text { Number of } \\
\text { participants }\end{array}$ & Type of primary care clinicians \\
\hline Butler (2008) [16] & $\begin{array}{l}\text { Wales (United } \\
\text { Kingdom) }\end{array}$ & $\begin{array}{l}\text { Semi-structured } \\
\text { qualitative interviews }\end{array}$ & $\begin{array}{l}\text { A test to distinguish bacterial } \\
\text { from viral infections using a } \\
\text { finger-prick blood test }\end{array}$ & $\begin{array}{l}\text { No experience - participants discussed } \\
\text { their perspectives on possible introduction } \\
\text { of the POCT }\end{array}$ & 40 & GPs \\
\hline Cals (2010) [17] & The Netherlands & $\begin{array}{l}\text { Semi-structured } \\
\text { qualitative interviews }\end{array}$ & $\begin{array}{l}\text { C-reactive protein POCT for } \\
\text { lower respiratory tract infection } \\
\text { and other common infections }\end{array}$ & $\begin{array}{l}\text { All participants had been using the POCT } \\
\text { for nearly } 3 \text { years at the time of interview } \\
\text { as part of a randomized trial }\end{array}$ & 20 & GPs \\
\hline Cals (2009a) [18] & The Netherlands & $\begin{array}{l}\text { Semi-structured } \\
\text { qualitative interviews }\end{array}$ & $\begin{array}{l}\text { C-reactive protein POCT to } \\
\text { differentiate serious from } \\
\text { self-limiting lower respiratory } \\
\text { tract infection }\end{array}$ & $\begin{array}{l}10 \text { participants had used the POCT for at } \\
\text { least two years at the time of interview as } \\
\text { part of a randomized trial; } 10 \text { participants } \\
\text { had no experience }\end{array}$ & 20 & GPs \\
\hline Gillam (1997) [19] & United Kingdom & $\begin{array}{l}\text { Semi-structured } \\
\text { interviews and a } \\
\text { focus group }\end{array}$ & $\begin{array}{l}\text { A range of POCTs including } \\
\text { haematology (full blood count, } \\
\text { platelets); chemical pathology } \\
\text { (sodium, potassium, urea, } \\
\text { creatine); glucose, cholesterol; } \\
\text { bilirubin, alkaline phosphatase, } \\
\text { aspartate transaminase; creatine } \\
\text { kinase }\end{array}$ & $\begin{array}{l}\text { Participants worked in a health centre } \\
\text { where POCTs were piloted; a nurse took } \\
\text { blood samples using venipuncture, they } \\
\text { were analysed onsite, and the results } \\
\text { were made available to the GP at the end } \\
\text { of surgery or immediately if requested }\end{array}$ & Unknown & GPs \\
\hline Glover (2008) [20] & Australia & $\begin{array}{l}\text { Group discussions + } \\
\text { individual interviews }\end{array}$ & $\begin{array}{l}\text { INR (international normalised } \\
\text { ratio) fingerstick test for } \\
\text { monitoring patients on warfarin }\end{array}$ & $\begin{array}{l}\text { No experience (this is not stated explicitly } \\
\text { but is assumed) }\end{array}$ & $\begin{array}{l}33 \text { participants in } \\
\text { total; unknown } \\
\text { how many were } \\
\text { GPs and nurses }\end{array}$ & $\begin{array}{l}\text { Hospital pharmacists, specialists, } \\
\text { nurses, GPs. We included only the } \\
\text { attitudes of GPs and nurses in the } \\
\text { review (nurses treated patients in } \\
\text { their homes as well as in hospital) }\end{array}$ \\
\hline Stone (2007) [21] & United Kingdom & $\begin{array}{l}\text { Semi-structured } \\
\text { qualitative interviews }\end{array}$ & $\begin{array}{l}\text { HbA1c (glycated haemoglobin) } \\
\text { finger-prick test for patients with } \\
\text { type } 2 \text { diabetes }\end{array}$ & $\begin{array}{l}\text { Participants took part in a pragmatic, } \\
\text { open, randomized controlled trial, where } \\
\text { they gave some patients usual care and } \\
\text { others POCTs for } 1 \text { year }\end{array}$ & 11 & GPs, practice nurses \\
\hline Wood (2011) [22] & $\begin{array}{l}\text { Belgium, Hungary, } \\
\text { Spain, Wales, Poland, } \\
\text { Italy, England, Norway, } \\
\text { The Netherlands }\end{array}$ & $\begin{array}{l}\text { Semi-structured } \\
\text { qualitative interviews }\end{array}$ & $\begin{array}{l}\text { C-reactive protein POCT to aid } \\
\text { management of acute cough/ } \\
\text { lower respiratory tract infection }\end{array}$ & $\begin{array}{l}\text { Participants from Norway routinely used } \\
\text { the POCT; participants from other } \\
\text { countries had no experience }\end{array}$ & 80 & Primary care clinicians \\
\hline
\end{tabular}


Table 2 Quality appraisal of included studies

\begin{tabular}{lcccccc}
\hline & $\begin{array}{c}\text { Was the sample used in } \\
\text { the study appropriate to } \\
\text { its research question? }\end{array}$ & $\begin{array}{c}\text { Were the data } \\
\text { collected } \\
\text { appropriately? }\end{array}$ & $\begin{array}{c}\text { Were the data } \\
\text { analysed } \\
\text { appropriately? }\end{array}$ & $\begin{array}{c}\text { Can I transfer the } \\
\text { results of this study } \\
\text { to other settings? }\end{array}$ & $\begin{array}{c}\text { Does the study adequately } \\
\text { address potential ethical } \\
\text { issues, including reflexivity? }\end{array}$ & $\begin{array}{c}\text { Overall: is what } \\
\text { the researchers } \\
\text { did clear? }\end{array}$ \\
\hline Butler [16] & Yes & Yes & Yes & Yes & No & No \\
Cals [17] & Yes & Yes & Yes & Yes & No & Yes \\
Cals [18] & Yes & Yes & Yes & Yes & No \\
Gillam [19] & Unclear & Unclear & Unclear & Unclear & No & No \\
Glover [20] & Unclear & Yes & Yes & Unclear & Yes & No \\
Stone [21] & Yes & Yes & Yes & Yes & Yes \\
Wood [22] & Yes & Yes & Yes & Yes &
\end{tabular}

[20]). In one study GPs raised concerns that they would be liable medico-legally for any problems arising from inaccurate results [19] (note this study was poorly described and it is not possible to assess its rigour).

Although POCTs were perceived on the whole to enhance patient care (if tests were accurate), exceptions were noted. A small number of individuals believed that it was not important or always helpful to distinguish bacterial from viral infections, [16] that monitoring POCTs did not influence the outcome of a consultation, [21] or questioned the added diagnostic value [22]. Diagnostic POCTs would not be helpful when serious complications arise from viral illnesses [16]; and misleading results due to CRP not being raised in the early stages of illness, or due to false results, could lead to inappropriate diagnosis and treatment: "I see the disadvantage that a mistake or false results can come out as a result. So for instance there is a positive result.... But a different and hidden problem can be the cause" (Primary Care Clinician [22]). Usefulness of monitoring POCTs performed by nurses varied "according to the nurse's level of responsibility for making management changes and the availability of a doctor during nurseled clinics" (authors [21]). GPs in one study actually felt waiting for results from laboratory testing was advantageous because it gave them time to "defer decisionmaking while awaiting results, thereby 'allowing nature to take its course" (authors [19]) (note that this study was poorly described and trustworthiness of findings cannot be assessed).

2) Impact of POCTs on clinical practice more broadly

Further to the direct impact on diagnosis and treatment, POCTs were thought to have a wider-reaching impact. The immediacy of diagnostic POCT results could reduce reconsultations or phone calls regarding the same episode of acute illness $[17,22]$. Some GPs believed that consultations for future illnesses may also be reduced: "If you don't treat a patient with antibiotics [after CRP testing] and the complaints resolve spontaneously, I think that patients will tend

Table 3 Summary of how primary care clinicians' attitudes towards blood POCTs may act as facilitators and barriers to their adoption in primary care

\begin{tabular}{|c|c|c|}
\hline Theme & Facilitators to adoption of POCTs in primary care & Barriers to adoption of POCTs in primary care \\
\hline \multirow{3}{*}{$\begin{array}{l}\text { Impact of POCTs on decision-making, } \\
\text { diagnosis and treatment }\end{array}$} & Increased diagnostic certainty & Concerns about accuracy \\
\hline & More effective targeting of treatment (e.g. antibiotics) & Might not be helpful or alter consultations \\
\hline & & Possible misleading results \\
\hline \multirow[t]{3}{*}{$\begin{array}{l}\text { Impact of POCTs on clinical practice } \\
\text { more broadly }\end{array}$} & $\begin{array}{l}\text { Fewer re-consultations / phone calls for the same or } \\
\text { future episodes of illness }\end{array}$ & Over-reliance, undermining of clinical expertise \\
\hline & Enhanced confidence and job satisfaction & Cost, equipment maintenance, time \\
\hline & $\begin{array}{l}\text { Avoidance of missing or delayed results, and loss of } \\
\text { patients to follow-up }\end{array}$ & Usefulness limited to certain situations and patients \\
\hline \multirow{5}{*}{$\begin{array}{l}\text { Impact of POCTs on patient-clinician } \\
\text { relationship and perceived patient } \\
\text { experience }\end{array}$} & $\begin{array}{l}\text { Enhanced communication through discussing } \\
\text { immediate results }\end{array}$ & Possible patient dislike of testing \\
\hline & $\begin{array}{l}\text { Increased patient education and self-management of } \\
\text { chronic conditions }\end{array}$ & Patient anxiety resulting from intermediate results \\
\hline & Shared decisions with patients (e.g. antibiotic prescription) & \\
\hline & Greater reassurance and satisfaction for patients & \\
\hline & Patient confidence in clinicians' decisions & \\
\hline
\end{tabular}


to wait and see and not consult the doctor again for the next similar illness episode. So what we hope is that this management including CRP will lead to fewer consultations or repeat consultations for new infections" (GP [17]). Advantages of monitoring POCTs in terms of future consultations were "avoidance of missing or delayed results and occasional loss of patients to follow-up" (authors [21]).

Immediacy of results could enhance clinicians' confidence and job satisfaction when using monitoring POCTs: "My confidence has actually grown in discussing the result with them... I feel it's sort of added and rounded off the consultation" (Nurse [21]).

There were some concerns that clinical practice could be negatively affected. Clinicians worried about potential over-reliance on diagnostic POCTs, $[17,22]$ undermining of clinical expertise, and over-testing: "Perhaps it's being used a bit too often. I think you need to be careful about that" (GP [17]); "The disadvantage is that doctors may rely more on test results than on clinical judgement" (Primary Care Clinician [22]); "There's a risk that you let the test determine your management. In the end, what matters is the person who's sitting there and what you hear and what you find on physical examination" (GP [17]).

Clinicians also expressed concerns that POCTs could only be used intermittently and in certain situations and patients $[16,18,20]$ : "for example, in situations where they were unsure of the aetiological cause on the basis of the clinical presentation, or in a situation of deadlock with a patient who definitely wanted antibiotics" (authors [16]).

Concerns regarding feasibility included cost, $[16,19,21,22]$ maintenance of equipment, [16] quality control, [19] time $[16,17,22]$ and organisational issues (for example interference in nurse activities) [17]. More positively, POCT devices were described as user-friendly, $[17,21]$ and in some cases as having "very little influence on their [GPs'] workload" (authors [17]).

3) Impact of POCTs on the patient-clinician relationship and perceived patient experience

Participants felt that being able to discuss results of monitoring POCTs with patients immediately was beneficial for patient-clinician communication, and determining the most appropriate treatment plan [21]: "you can instigate changes in treatment there and then and discuss it with the patient" (Nurse [21]). POCTs could therefore enhance patient education and self-management of chronic conditions [20,21]: "It'd be great for patient advocacy and empowering them to take some responsibility for their own health care" (Nurse [20]).

Regarding diagnostic POCTs, it was believed that patients would be convinced, reassured and more satisfied in their GP's decisions if POCTs had been used, compared to if they had received no test [16-18,22]: "then you can justify what you are saying to the patient. Because nowadays, patients want the evidence as well" (GP [16]). In particular, a test result confirming a GP's decision not to prescribe antibiotics would help them to "sell" this decision to patients [16] and manage patient expectations for antibiotics, [22] leading to shared decisions with patients [18]. This was perceived by GPs to help preserve a trusting doctor-patient relationship [17]. GPs with different levels of experience of using diagnostic POCTs had similar perceptions that they would help to reassure patients and lead to more effective targeted treatment without alienating or upsetting patients $[16,18,22]$. GPs in one described that the POCT service "boosted the practice's image" [19] (note that this study is poorly described and rigour cannot be assessed).

Although it was widely believed that patients would like to have POCTs available, concerns that patients may not like testing were mentioned by a minority of participants, $[16,17,22]$ with children mentioned in particular [16]. Furthermore, some GPs were worried about difficulty interpreting and explaining diagnostic test results, [22] particularly intermediate results [17] which could increase uncertainty in patients: "the patient may think that their blood was not entirely OK, so that may make them insecure and worried" (GP [17]). With regards to interpreting test results, "a solid training session was highly valued” (authors [17]).

\section{Discussion \\ Main findings}

Despite considerable heterogeneity regarding the specific tests involved and their purpose (primarily diagnosis or monitoring), we found commonalities in primary care clinicians' attitudes towards POCTs. Overall, these tests were believed to increase diagnostic certainty, help target treatment, educate and empower patients, and improve the relationship between clinicians and patients by enhancing communication and shared decision-making. A major concern was the need for accurate tests. Clinicians were also concerned about cost, over-reliance - in that POCTs could undermine clinical skills - and limited usefulness. Table 3 summarizes these issues and highlights how they may act as facilitators and barriers to widespread adoption of POCTs in primary care.

The number of included studies was small, and there was heterogeneity regarding the type of test, its purpose, the type of primary care clinicians participating, and whether or not they had practical experience of using POCTs. This may limit generalizability of our results to other tests and settings. However, we identified commonalities; and clinicians with experience of using POCTs routinely (Norwegian GPs [20]) described similar benefits and concerns to those who had experience of using them only in the context of a trial, and those who had not used 
them. We have highlighted which attitudes were specific to only diagnostic or monitoring POCTs; for example more effective targeting of antibiotics with diagnostic POCTs, and enhanced patient self-management with monitoring POCTs. Each of the three main themes applied to both diagnostic and monitoring POCTs.

Some of these issues are not unique to POCTs, but also apply to laboratory testing in general; for example concerns that misleading results could lead to inappropriate diagnosis and treatment, and that testing is only useful in certain circumstances. However, the majority apply to POCTs specifically due to speed of obtaining (and having to interpret) test results having an immediate impact, for example by improving diagnostic decision-making and communication with patients.

Despite the wealth of POCTs available there has not been widespread adoption of POCTs in primary care to date, at least in most countries. In addition to the barriers to POCT use identified here, other reasons for lack of widespread use may include lack of needs assessments of primary healthcare clinicians, resulting in discordance between the tests that they want/would use frequently, and those that are produced. Furthermore, multiple steps are needed between the development of new diagnostic tests and their adoption into clinical practice: tests can reach the market with limited evaluation of clinical utility or cost-effectiveness in primary care populations [23]. For example, evaluation of readily available POCTs has been inconclusive regarding cost-effectiveness compared to standard laboratory testing, $[24,25]$ and uncertain regarding their clear role in primary care [24].

\section{Comparison with existing literature}

A quantitative study of patient satisfaction with POCTs in general practice similarly highlighted strengthened relationships between patients and GPs, and motivation of patients to better manage chronic conditions [26]. GPs in another survey study supported the use of POCTs in general practice due to improved convenience, patient care and efficiency [27]. Also in keeping with our findings, Hobbs [28] concluded that there are "clinical niches" where POCTs are most likely to influence practice, and that these must be found in order that their potential is realised; and GPs' use of CRP POCTs was found to significantly reduce antibiotic prescribing [6].

\section{Strengths and limitations}

This is the first systematic review, to our knowledge, to explore primary care clinicians' attitudes towards a rapidly growing technological area in primary care, namely blood POCTs. We used a comprehensive search strategy, and by synthesising qualitative rather than quantitative studies we were able to gain an in-depth understanding of clinicians' perspectives.
We limited our review to blood POCTs in primary care, high income country settings. Future research could compare attitudes amongst countries which have different primary care health systems; also the attitudes of other frontline clinicians such as paramedics or emergency department staff. We focused on blood tests; further research is needed to confirm whether the issues raised here apply to other types of POCTs (for example urine tests, respiratory samples).

Thematic synthesis is dependent on the quality of included studies, the themes and participant quotes which authors of these studies choose to present, and the interpretations of the reviewers. One of the included studies was poorly described and it was not possible to assess its rigour. Consequently we were cautious in interpreting its findings. Additionally it was relatively old (published 10 years before the next oldest study), and the POCTs used blood obtained by venipuncture rather than fingerprick blood samples, meaning that the findings might be out of date for current POCT practices. We minimised bias in selectivity and interpretation of synthesis results by having two authors independently extract and explore themes in the data, and discussing themes between all authors to reach consensus. We found broad agreement between our descriptive themes and the conclusions of individual studies. None of us were involved in the included studies in any way. The main reviewers $(\mathrm{CJ}, \mathrm{JH})$ are not clinicians and did not have experience or preconceived opinions regarding POCTs, which strengthened our approach. To counter the risk that participants' quotes were interpreted differently from how they were intended, other authors who are primary care clinicians $(\mathrm{MT}, \mathrm{CH})$ verified the themes and interpretations. All of the authors are involved in identifying and evaluating emerging diagnostic technologies. We are interested in the potential for them to positively impact primary care, and it is possible that we hold underlying positive attitudes towards the implementation of POCTs. However, we were careful to identify negative as well as positive attitudes towards POCTs, and we have reported these thoroughly.

There is a risk of publication bias, in that studies demonstrating negative attitudes or impacts of POCTs may be less likely to be published. In three of the included studies, manufacturers loaned or provided equipment, $[17,18,21]$ although the authors state that the manufacturers had no role in the study or preparing of the manuscript. Despite the risk of bias, we identified a balance of barriers and facilitators to the widespread use of POCTs.

\section{Conclusions}

A multitude of POCTs are on the market and new ones are constantly being developed. These are of interest to primary healthcare clinicians who face growing pressures 
to perform more tests, more rapidly, reducing referrals and risk of diagnostic errors [23]. The findings of this review confirm that from the perspectives of primary care clinicians, likely benefits of introducing POCTs include increased diagnostic certainty, more efficient care, and fewer (re)consultations.

This review has also highlighted several clear barriers to the implementation of POCTs. If they are to be implemented more widely, these barriers must be addressed, some by primary care and others elsewhere. The accuracy of POCTs in primary care populations, and the way this is presented to clinicians, must be addressed by industry. Policy makers and clinicians should carefully consider the role and impact of POCTs in primary care; in particular, attention should be paid to impacts on GPs' roles so that clinical expertise is enhanced rather than undermined. Furthermore, it is essential to define more clearly the different situations and patients in which POCTs are useful. In the context of reductions in health service funding, and importance of primary care commissioning, attention must be paid to how the costs of POCTs will be funded.

This review highlights that exploring the attitudes of primary care clinicians is integral to understanding if and how POCTs may become adopted more widely. It is possible that emphasizing the benefits and addressing the concerns highlighted in this review may lead to wider adoption of POCTs in primary care.

\section{Additional file}

Additional file 1: Search strategy: Medline (OvidSP). Primary care clinicians' attitudes towards point of care testing.

\section{Competing interests}

The authors declare that they have no competing interests.

\section{Authors' contributions}

All authors conceptualized the study and participated in study design. NR conducted the literature search. $\mathrm{CJ}$ and $\mathrm{JH}$ determined eligibility of studies, and extracted and synthesized the data. MT checked eligibility of included studies. CJ drafted the manuscript. All authors read and approved the final manuscript.

\section{Acknowledgments}

This publication presents independent research funded by the National Institute for Health Research (NIHR) under its Programme Grants for Applied Research funding scheme (RP-PG-0407-10347). The views expressed in this publication are those of the author(s) and not necessarily those of the NHS, the NIHR or the Department of Health. The funding body had no role in study design; collection, analysis or interpretation of data; writing the manuscript; or the decision to submit.

\section{Author details}

'Department of Primary Care Health Sciences, University of Oxford, Woodstock Road, Oxford, UK. ²Bodleian Health Care Libraries, Knowledge Centre, University of Oxford, Headington, Oxford, UK.

Received: 23 May 2013 Accepted: 29 July 2013

Published: 14 August 2013

\section{References}

1. Tran NK, Kost GJ: Worldwide point-of-care testing: compendiums of POCT for mobile, emergency, critical, and primary care and of infectious diseases tests. Point of Care 2006, 5(2):84-92.

2. Price CP, StJohn A, Kricka LJ: Point-of-care testing. Needs, opportunity, and innovation, 3rd edn. Washington DC: AACC Press; 2010.

3. Bubner TK, Laurence CO, Gialamas A, Yelland LN, Ryan P, Willson K, Tideman P, Worley P, Beilby JJ: Effectiveness of point-of-care testing for therapeutic control of chronic conditions: results from the PoCT in General Practice Trial. Med J Aust 2009, 190(11):624-626.

4. Price $C P$, Kricka LJ: Improving healthcare accessibility through point-ofcare technologies. Clin Chem 2007, 53(9):1665-1675.

5. Laurence C, Gialamas A, Yelland L, Bubner T, Ryan P, Willson K, Glastonbury B, Gill J, Shephard M, Beilby J: A pragmatic cluster randomised controlled trial to evaluate the safety, clinical effectiveness, cost effectiveness and satisfaction with point of care testing in a general practice setting rationale, design and baseline characteristics. Trials 2008, 9:50.

6. Cals JW, Butler CC, Hopstaken RM, Hood K, Dinant GJ: Effect of point of care testing for $\mathrm{C}$ reactive protein and training in communication skills on antibiotic use in lower respiratory tract infections: cluster randomised trial. BMJ (Clinical research ed) 2009, 338:b1374.

7. Cals JW, Ament AJ, Hood K, Butler CC, Hopstaken RM, Wassink GF, Dinant GJ: C-reactive protein point of care testing and physician communication skills training for lower respiratory tract infections in general practice: economic evaluation of a cluster randomized trial. J Eval Clin Pract 2011, 17(6):1059-1069.

8. Hilton S, Rink E, Fletcher J, Sibbald B, Freeling P, Szczepura A, Davies C, Stilwell J: Near patient testing in general practice: attitudes of general practitioners and practice nurses, and quality assurance procedures carried out. The British journal of general practice: the journal of the Royal College of General Practitioners 1994, 44(389):577-580.

9. Wong S, Wilczynski NL, Haynes RB: Developing optimal search strategies for detecting clinically relevant qualitative studies in MEDLINE. Medinfo 2004, 11(pt 1):311-316

10. Booth A: Searching for studies. In Supplementary guidance for inclusion of qualitative research in Cochrane Systematic Reviews of Interventions Version 1 Edited by Noyes J, Booth A, Hannes K, Harden A, Harris J, Lewin S, Lockwood C. Cochrane Collaboration Qualitative Methods Group; 2011. http://cqim.cochrane.org/supplemental-handbook-guidance.

11. Dixon-Woods M, Bonas S, Booth A, Jones DR, Miller T, Sutton AJ, Shaw RL, Smith JA, Young B: How can systematic reviews incorporate qualitative research? A critical perspective. Qualitative research 2006, 6(1):27-44.

12. Barnett-Page $E$, Thomas J: Methods for the synthesis of qualitative research: a critical review. BMC Med Res Methodol 2009, 9(1):59.

13. Lucas PJ, Baird J, Arai L, Law C, Roberts HM: Worked examples of alternative methods for the synthesis of qualitative and quantitative research in systematic reviews. BMC Med Res Methodol 2007, 7(1):4.

14. Thomas J, Harden A: Methods for the thematic synthesis of qualitative research in systematic reviews. BMC Med Res Methodol 2008, 8(1):45.

15. Kruper $A$, Lingard $L$, Levinson W: Critically appraising qualitative research. BMJ 2008, 337:a1035.

16. Butler CC, Simpson S, Wood F: General practitioners' perceptions of introducing near-patient testing for common infections into routine primary care: a qualitative study. Scand J Prim Health Care 2008, 26(1):17-21.

17. Cals JW, Chappin FH, Hopstaken RM, van Leeuwen ME, Hood K, Butler CC, Dinant GJ: C-reactive protein point-of-care testing for lower respiratory tract infections: a qualitative evaluation of experiences by GPs. Fam Pract 2010, 27(2):212-218.

18. Cals JW, Butler CC, Dinant GJ: 'Experience talks': physician prioritisation of contrasting interventions to optimise management of acute cough in general practice. Implementation science: IS 2009, 4:57.

19. Gillam S, Freedman D, Naughton B, Ridgwell P, Singer R: An evaluation of near patient testing in general practice. J Eval Clin Pract 1997, 4(2):165-169.

20. Glover S, Bajorek BV: Exploring point-of-care testing of capillary blood in warfarin management. Journal of Pharmacy Practice and Research 2008, 38(4):300.

21. Stone MA, Burden AC, Burden M, Baker R, Khunti K: Near patient testing for glycated haemoglobin in people with Type 2 diabetes mellitus managed in primary care: acceptability and satisfaction. Diabetic medicine: a journal of the British Diabetic Association 2007, 24(7):792-795. 
22. Wood F, Brookes-Howell L, Hood K, Cooper L, Verheij T, Goossens H, Little P, Godycki-Cwirko M, Adriaenssens N, Jakobsen K, et al: A multi-country qualitative study of clinicians' and patients' views on point of care tests for lower respiratory tract infection. Family practice 2011, 28(6):661-669.

23. Thompson M, Pluddemann A, Price CP, Heneghan C: Emerging diagnostic technologies in primary care: what's on the horizon? The British journal of general practice: the journal of the Royal College of General Practitioners 2013, 63(609):177-178

24. Pluddemann A, Heneghan C, Price CP, Wolstenholme J, Thompson M: Pointof-care blood test for ketones in patients with diabetes: primary care diagnostic technology update. The British journal of general practice: the journal of the Royal College of General Practitioners 2011, 61(589):530-531.

25. Pluddemann A, Thompson M, Price CP, Wolstenholme J, Heneghan C: Point-of-care testing for the analysis of lipid panels: primary care diagnostic technology update. The British journal of general practice: the journal of the Royal College of General Practitioners 2012, 62(596):e224-226.

26. Laurence CO, Gialamas A, Bubner T, Yelland L, Willson K, Ryan P, Beilby J: Patient satisfaction with point-of-care testing in general practice. The British journal of general practice: the journal of the Royal College of General Practitioners 2010, 60(572):e98-104.

27. Cohen J, Piterman L, McCall LM, Segal L: Near-patient testing for serum cholesterol: attitudes of general practitioners and patients, appropriateness, and costs. Med J Aust 1998, 168(12):605-609.

28. Hobbs R: Near patient testing in primary care. BMJ (Clinical research ed) 1996, 312(7026):263-264

doi:10.1186/1471-2296-14-117

Cite this article as: Jones et al:: Primary care clinicians' attitudes

towards point-of-care blood testing: a systematic

review of qualitative studies. BMC Family Practice 2013 14:117.

\section{Submit your next manuscript to BioMed Central and take full advantage of:}

- Convenient online submission

- Thorough peer review

- No space constraints or color figure charges

- Immediate publication on acceptance

- Inclusion in PubMed, CAS, Scopus and Google Scholar

- Research which is freely available for redistribution 